\title{
USING AI TO PERSONALISE EMOTIONALLY APPEALING ADVERTISEMENT
}

\author{
Emmanuel Mogaji ${ }^{1[0000-0003-0544-4842]}$, Sunday Olaleye ${ }^{\text {[0000-0002-0266-3989] }}$ and Dandison \\ Ukpabi ${ }^{3[0000-0002-5081-354 X]}$ \\ ${ }^{1}$ University of Greenwich, London, UK \\ ${ }^{2}$ University of Oulu, Oulu, Finland \\ ${ }^{3}$ University of Jyväskylä, Jyväskylä, Finland
}

\begin{abstract}
Personal data and information collected online by companies can be used to design and personalise advisements. This chapter extends existing research into the online behavioural advertising by proposing a model that incorporates artificial intelligence and machine learning into developing emotionally appealing advertisements. It is proposed that big data and consumer analytics collected through AI from different sources, will be aggregated to have a better understanding of consumers as individuals. Personalised emotionally appealing advertisements will be created with this information and shared digitally using pragmatic advertising strategies. Theoretically, this chapter contributes towards the use of emerging technologies such as AI and Machine Learning for Digital Marketing, big data acquisition, management and analytics and its impact on advertising effectiveness. With customer analytics making up a more significant part of big data use in sales and marketing and GDPR ensures data are legitimately collected and processed, there are practical implications for Managers as well. Acknowledging that this is a conceptual model, the critical challenges are presented. This is open for future research and development both from academic, digital marketing practitioners and computer scientist.
\end{abstract}

Keywords: Artificial intelligence, Online Behavioral Advertising, Personalized ad, Emotional Appeal, Social Media.

\section{Introduction}

With the changing dynamics in digital marketing, brands are having unprecedented access to information about their customers, and they can use this technology to influence consumer behaviour (Dwivedi, et al., 2015). These dynamics includes personalisation - creating advertisements that match with customers characters and interest (Tran, 2017), however, there has been previous studies that uncovered a number of favourable and unfavourable consumer responses to ad personalization. The moderating factors

\footnotetext{
${ }^{1}$ Corresponding Author: Emmanuel Mogaji. E.o.mogaji@greenwich.ac.uk
} 
that strengthen or weaken these effects are still mostly missing (Bleier \& Eisenbeiss, 2015), as just putting a name on an advertisement is not enough to guarantee a positive response (Li \& Liu, 2017).

To fill this void, we propose the possibilities of using artificial intelligence (AI) to extract information about customers, generate advertisements that will appeal to them and shared digitally. This possibility moves away from the idea of personification just by names (Tran, 2017) or past online experiences (Bleier \& Eisenbeiss, 2015) but personalising with emotionally appealing features liked sounds, images, and colours which customers can engage with on a personal level.

Specifically, the study aims to develop and extend existing research into the online behavioural advertising by proposing a model that incorporates artificial intelligence and machine learning into developing emotionally appealing advertisements. Theoretically, this chapter contributes towards the use of emerging technologies such as AI and Machine Learning for Digital Marketing, big data acquisition, management and analytics and its impact on advertising effectiveness.

Subsequent sections present a brief review on personalised advertisement and emotional appeals, followed by existing examples of AI initiatives to justify the possibilities of this idea. The theoretical framework and the contribution of the study is thereafter provided. The theoretical framework is followed by the keys challenges and a conclusion of the study.

\section{Personalised Advertisement}

It is no longer news that advertisers are increasingly monitoring people's online behaviour and using the information collected to target them with relevant marketing communications. This phenomenon is called online behavioural advertising (OBA). Boerman, et al. (2017, p. 364) defined OBA as 'the practice of monitoring people's online behaviour and using the collected information to show people individually targeted advertisements'. Advertisers see it as part of the future of advertising, one of the most important new ways of reaching targeted audiences (Boerman, et al., 2017; Kumar \& Gupta, 2016).

With regards to data used to create OBA, Boerman, et al. (2017) argued that personalisation is based on the types and amount of personal data that being used. The types of personal data include browsing data or search history while amount refers to the intensity and combination of that information. Boerman, et al. (2017) noted that OBA differs from other types of online advertising because of the covert nature of collecting personal data as this may be harmful and unethical, as consumers are unaware of the tactics advertisers put in place to collect the data. There have been concerns raised 
about privacy as this involves collecting, using, and sharing personal data and Consumer responses toward OBA (Baek and Morimoto (2012).

Often consumers feel the advertisement are boring, intrusive or not interested at all and thereby they put up a defence mechanism by using as ad blockers, skipping the advertisements or just ignoring it (Mogaji \& Danbury, 2017) and this has economic implication as the advertisements are not received as intended. Baek and Morimoto (2012) found that this ad irritation increases ad scepticism, which consequently leads to more avoidance of OBA, however, there are evidence that advertisements which target individuals with their interest receive a higher level of engagement. Tucker (2014) found that Facebook ads which appeal to a person's interest led to higher click-through rates and likewise Aguirre et al. (2015) showed that moderately personalized Facebook ads increased click-through rates which highlights the possibilities of embedded emotional appeals in personalised advertisements to reach out to prospective customers as Mogaji (2018) found that the lack of interest and congruency with personal values are one of the reasons why advertisements are ignored.

\section{Emotional Appeals in Advertisement}

Emotionally appealing advertisements are meant to appeal to consumers' heart, making them feel special, and a part of the brand (Mogaji, 2018; Mogaji, et al., 2018). Aaker and Stayman (1992) described emotional advertisements as those serving mainly to elicit affective responses. Emotionally appealing advertisements have been found to increase loyalty and make brands distinct (Panda, et al., 2013). Emotional appeals are incorporated into advertisements in the forms of text, images, background music and voiceover to attract viewers' attention and provide information about the brand (Mogaji, 2018).

Images are considered very important as visual cues for emotional appeals. Emotionally-appealing images can be considered as the primary channel of communication, replacing copy and headlines as the most crucial element in advertisements (Mezo, 1997; Salander, 2010; Brader, 2006). Colours are also considered critical graphic elements in arousing emotions and generating attention toward the advertisement across various media. They create an emotional tone and can also be a dominant feature within the advertisement (Salander, 2010; Mogaji, 2016).

The text used in advertisements are considered as a verbal component, it includes all the headlines, taglines, and copy used to narrate the marketing communications. These elements can also evoke positive emotional appeals like excitement and joy, or negative feelings like fear and shame, as observed by Stanton and Guion (2013). Emotional appeals can also be presented through what consumers hear in advertisements (Mogaji \& Farinloye, Attitudes towards brands and advertisements: qualitative and thematic analysis of social media data, 2017; Mogaji, Farinloye, \& Aririguzoh, Factors shaping 
attitudes towards UK bank brands: An exploratory analysis of social media data, 2016); this varies from background music, a voice-over, and even the dialogue in the advertisement. Popular songs are effective at invoking an emotional response (Schiffer, 2015). Advertisers often use familiar and popular sounds to engage with customers, giving rise to a sense of excitement, happiness, and love. In addition, a voice-over can add to the complexity, ambiguity, and hybridity of audio elements concerning arousing emotional responses $(\mathrm{Li}, 2017)$.

\section{$4 \quad$ Artificial Intelligence in Advertisement}

The ability to hold together the seemingly inconsistent components of an advertisement, making a new function, is considered creativity (O'Guinn, et al., 2006). Consumers who lack interest in advertisements have challenged advertisers to develop campaigns that can "cut through the clutter" in a highly saturated media space. Advertiser relies on using personal data to target customers and beat the media clusters. Ha (1996) described "media cluster" as the quantity, competitiveness, and intrusiveness of advertisements. For any advertisement to stand out in this cluster, creativity plays a prominent role by providing a strategic approach to developing an appealing advertisement (Decrop, 2007).

Personal data and information legitimately collected online by companies can be used to design and personalize advisements that appeals to consumers emotions and shared online. This process differs from the highly personalized and rational data such as age, gender, and location which Aguirre et al. (2015) found to have a reduced clickthrough rate but things that emotionally appeals to individuals like their choice of colours, images being used and background music.

Artificial intelligence (AI) is the umbrella term used to describe the ability of machines to complete tasks that they can increasingly perform better over time (Williams, 2018). It can collect data from different sources, identify patterns and be able to provide actionable insights. It is proposed that with big data and consumer analytics collected through AI from different sources will be aggregated to have a better understanding of consumers as individuals.

This aggregation can be information from the web and mobile analytics, social analytics media analytics, customer journey analytics - using CRM and marketing system data to track known individuals over time and voice of the customer analytics - mining customers' perceptions and opinions (Ukpabi, Karjaluoto, Olaleye, \& Mogaji, 2018; Kihn, 2016). Emotional cues about the consumers can be deduced from these sources. The type of type of music they listen to, their interest or hobbies, celebrities they are more likely to engage with, places they are more likely to go for a holiday, the types of pets or animals they like. These are features that go beyond behaviours based on past 
and advertisements. Big data analytics provide numerous other insights regarding customer behaviour (Datameer, 2018).

With this information, it is anticipated AI will be able to develop a customised advertisement which customers will find emotionally appealing by picking and choosing from a bouquet of creative elements and fitting them into the frame to send out to the customers. These advertisements will be shared digitally highlighting an implication on programmatic advertising, a process of buying advert automatically, with computers using data to decide which to buy and how much to pay for them (Kulbok, 2017). Programmatic provides a single view of the consumer and single point of media planning and buying across all digital media channels and allows marketers to leverage their own data, media, and technology (Dawson \& Lamb, 2016). AI can make programmatic advertising more efficient, faster and easier to implement (Faggella, 2017), ensuring that targeted advertisements are optimized and delivered as anticipated.

\section{Present works using AI}

FontJoy is a website that uses machine learning to perfectly pair fonts (Fontjoy, 2018). The website works by analyzing letterforms, sorting them within its mind, and then systematically finds fonts from a database of more than 1,800 fonts that share similarities (Wilson, 2017). The mixing and matching typefaces provides the aesthetics and pleasing feels a human designer would want (Plummer, 2017).

EyeQuant utilizes machine learning to evaluate the usability of websites. It fuses leading neuroscience research with AI and eye-tracking technology to accurately predict how people will react to digital designs (Eyequant, 2018). The algorithm analyses the visual characteristics of an ad from simple features like colours and contrasts, to more complex factors like object recognition (Diaz, 2018). In one click, EyeQuant generates an instant analysis of the design's visual attention, clarity and emotional impact (Eyequant, 2018).

Netflix collects a huge amount of personal data, and they have been able to use this through machine learning and artificial intelligence to automatically customize their movie posters to fit the personal preference of viewers (Chandrashekar, et al., 2017). By using different artwork and imagery to portray the titles of each of their members to highlight the aspects of a title that is specifically relevant to them, they consider themselves differs from traditional media offerings. They do not have one product but over 100 million different products with one for each of their members with personalized recommendations and personalized visuals.

Semantic Soft Segmentation is an AI-assisted image editing tool that automates object selection which was developed by MIT's Computer Science and Artificial Intelligence Lab (Aksoy, et al., 2018). The tool offers an accurate pre-segmentation of the image and can speed up the editing process by providing an intermediate image 
representation. While acknowledging this innovation as a step in the right direction, Greene (2018) noted that the future of image and video editing is certainly AI, but we are not quite there as the editor does not work with video just yet and it takes about four minutes to process an image which can still be achieved faster using photoshop.

Bidalgo recently introduced 'Creative AI' as part of its self-serve advert automation platform (Bidalgo, 2018). It uses image and video recognition technology to analyze every component of an advertiser's creative down to each pixel to them develop ad creatives that drive campaign goals. Creative AI uses Bidalgo's proprietary AI-based algorithms to break down the DNA of successful ad creatives by analyzing dozens of variables including images, colours, promotions, contrast, concepts, copy, and more (Takahashi, 2018).

Persado offers AI software to instantly generate better performing email subject lines through emotional language (Persado, 2018). Their new tool uses deep learning algorithms to create an emotional profile for individual users based on previous campaigns, then generates the corresponding language to personalize the message. This step includes options for email, display advertising, social advertising, landing pages, SMS and push notifications in as many as 23 languages. Phrasee also offers a similar tool. They use advanced end-to-end Deep Learning to optimize engagement results on an on-going basis. Phrasee AI learns from customers' response metrics, quantifies and optimises language that makes the audience engage with their messages. They promised that using a better language in marketing communications will lead to more customer engagement and make brands more money (Phrasee, 2018).

These examples highlight the possibilities of creating a frame to fits in features of advertisements like images, text, and colours (Netflix), the images can be replaced through AI for every personalised advertisement (Semantic Soft Segmentation), the colours and fonts used in the advertisements can also be replaced as well (FontJoy). The textual content and copy of the advertisement can be customised (Persado and Phrasee). The overall look and creative elements of each advertisement can thereafter be checked (EyeQuant and Bidalgo). This advertisement can also build on the AI creative director developed by McCann Erickson in Japan (Doland, 2016), which is an AI used in creating advertisement but not personalised.

\section{Theoretical Framework}

To illustrate how this process will work, the five stages are presented in a cycle which starts from understanding the customer's online behaviour and ends with feedback which is used to shape the process and the machine further learns from it.

To practically illustrate this process, Figure 1 presents a fictitious advertisement from a Bank being sent to the prospective customer. This is a generic advert for a cash back which is being sent to all the customers. It is important to note that not all 
customers will be interested in this cash back offer or better still some will have preferences in what to claim cash back on.

\subsection{Understanding the Customers 'online behaviours}

With the adoption of this personalised emotionally appealing advertising strategy, AI can firstly extract data about the customer from different sources and touch points (Ukpabi, Karjaluoto, Olaleye, \& Mogaji, Influence of Offline Activities and Customer Value Creation on Online Travel Community Continuance Usage Intention, 2019). AI is able to group customers based on their online behaviour, financial status, and lifestyle. This includes if they have a pet by exploring if they have bought things for pets on a regular basis, the type of music they like perhaps from Spotify, the type of celebrity or influencers, their sports or recreational activities and many more.

\subsection{Developing the Advertisements}

The frame for the advertisements is prepared. This is created to allow spaces for all the creative elements. This can appear to be the most challenging section of the process whereby advertisements are developed to allows features to be changed by the AI algorithms. Like Netflix can personalise movie poster based on individual preferences there is an opportunity to change the actors and the headline. These modular arrangements can include related images, perhaps the customer favourite artist with their favourite background music, the right type of words, background colour and location, these are all details that are gathered from different sources which suggests that two people living in the same room with different preferences might not be seeing the same advertisement even if they are searching for the same product.

\subsection{Filling the frame}

Following on from step 1 here the machine knows what can specifically interest a customer's and step 2 that has got an advertisement frame that allows such flexibility. The advertisement frame is filled based on individual preferences by picking a related cash back offer text, with the right image and possibly the right background music. For example, the Single female customer who has a dog, an image of the dog (possible the same breed if known) is included in the advert, instead of receiving cash back offer about broadband, she received an offer for pet expenses and likewise for those receiving cash back offer for their internet, the image for a single male is different from a married male with children. This is where the creative features that arouses emotions are embedded. The choice of image, the choice of colour and even the background music are filled into the frame provided. 


\subsection{Sharing the Advertisements}

This personalised advertisements with emotional appealing features are distributed digitally to the targeted audiences. This could be on social media, websites or apps depending on which they engage more with (Gökerik, Gürbüz, Erkan, Mogaji, \& Sap, 2018). Programmatic advertising also plays a key role here - meeting the customers in the right place with the right messages that they find relevant and emotionally appealing enough to engage with. This is more personal and likely more engaging because it is specifically targeting the individual's need and not just a generic advertisement.

\subsection{Feedback and Evaluation}

Lastly, the effectiveness of this advertisements is monitored to see how the customers are engaging with it. How many of them are following the link to find out more about the offer? How many of them are sharing it with the network? Or how many of them are ignoring it? These insights can be used for machine learning and to improve the development and effectiveness of the advertisements and a better understanding of the customers. 


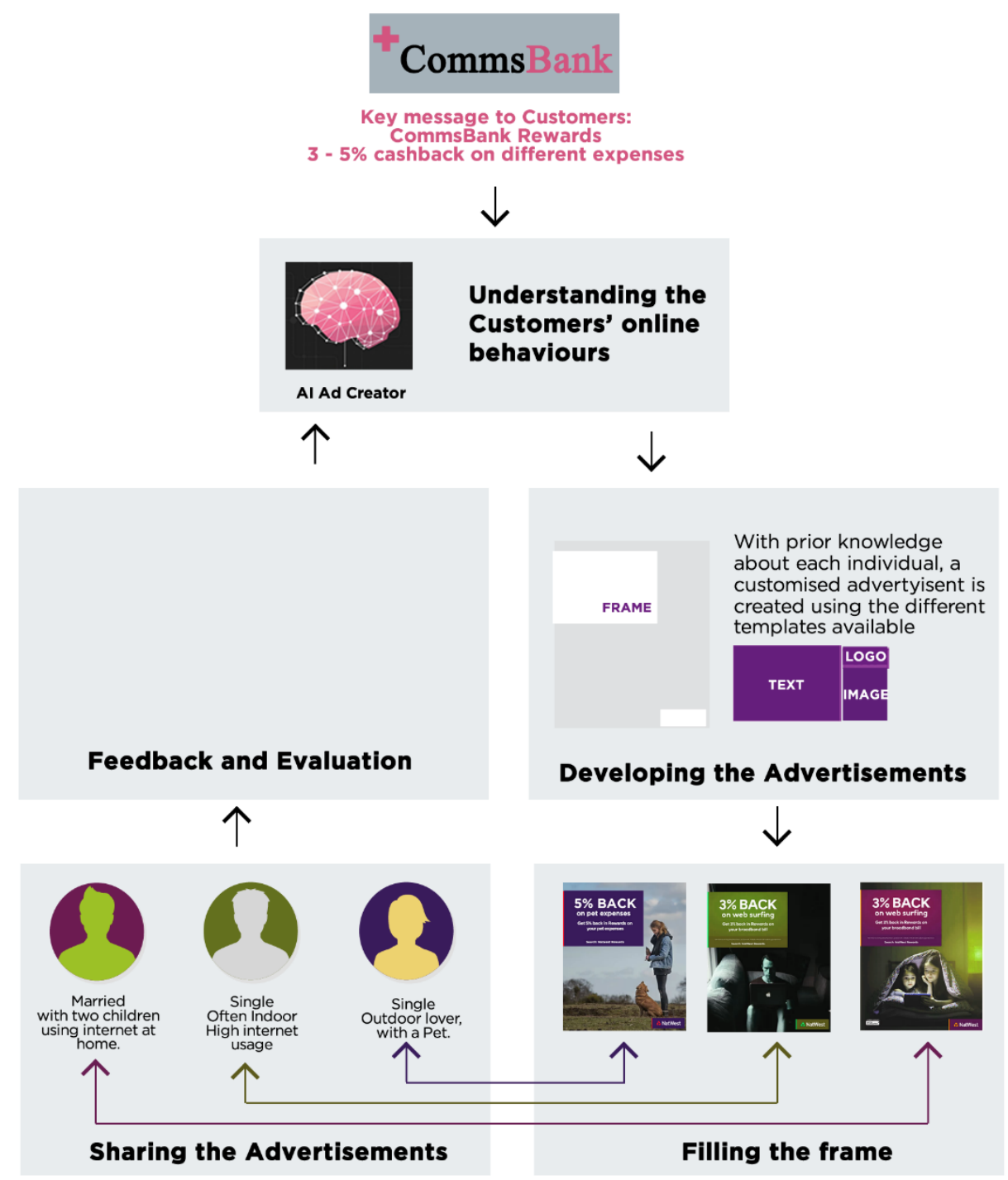

Fig.1. The Five stages of the proposed model

\section{$7 \quad$ Key Theoretical Contributions}

Though many prior studies have explored personalisation in advertisement across different domains, but there have been different conclusions (Li \& Liu, 2017), this study makes contribution towards a better understanding of personalisation and moving beyond the fundamental idea of just treating each message recipient as a unique entity 
(Kalyanaraman \& Sundar, 2006) but customising an advertisement with different creative elements that is based on their characteristics and preferences.

This chapter contributes towards the use of emerging technologies such as AI and Machine Learning for Digital Marketing, big data acquisition, management and analytics and its impact on advertising effectiveness. A contribution to knowledge and development of further insight into these growing areas of digital marketing which needs further research and understanding (Boerman, et al., 2017). Sentiment analysis, a form of Machine Learning can also be used to have a better understanding of attitude towards the advertisements and the brands (Mogaji \& Erkan, Insight into consumer experience on UK train transportation services, 2019).

The study also contributes towards a better understanding of emotional appeals and how it can be used better in advertisements, highlighting the potentials of artificial intelligence in creative advertisements, an improvement to OBA and programmatic. In addition, these digital innovations, whereby AI will be able to create emotionally appealing advertisements can be transferred to other sectors and industry.

\section{$8 \quad$ Key Implications for digital marketing practice}

The chapter presents an idea that collects and process a vast amount of data which encompasses both online searchers and personal interests. Customer analytics makes up $48 \%$ of big data use in sales and marketing (Columbus, 2016) which highlight there are new sources of data about the customers which present new opportunities for advertisers and plays an important role in the prediction of customer behaviour which they can use to achieve unprecedented value and competitive advantage over competitors (Hitchcock, 2018). The information is out there; advertisers need to be more open and transparent about collecting and using it.

It is however, paramount to note that this information will be obtained with the knowledge and consent of the data subject. Consumers have been worried about their privacy and OBA practices (Antón, et al., 2010) but this idea is anchored on the practicalities of General Data Protection Regulation (GDPR) which is a new set of standards designed to strengthen the control individuals have over their data. From May 2018, it became a legal requirement for all companies collecting and processing data need to adhere to the regulations in place or face a heavy fine up to $€ 20$ million or $4 \%$ of a company's global annual income (whichever is the larger amount). Organisations must specify the details about the collection and the customers must explicitly opt-in to allow personal data to be processed.

GDPR is aimed at solving the issues around privacy and transparency which have been the greatest concerns with OBA. Akbarpour (2018) warned that to stay compliant with the GDPR, organisations will need to either abandon the use of cookies to track 
online behaviour or obtain consent from their customers. Since the law has stipulated the need to get consent and advertisers are aware of the benefits of OBA, it is imperative to consider the implications for both academic and practitioners as there are inherent benefits for brands which use this well for their digital marketing campaign as scholars suggested that advertising will become more personalized and targeted and will involve more individual communication (Rust, 2016; Kumar \& Gupta, 2016).

The recent legislation about GDPR makes this study very relevant; it builds on the fact that consumers have allowed advertisers to purposefully observe their online behaviours and targeted them appropriately and this is more likely to offer a genuine interest in advertisements. In addition, personalization is generally considered an important strategy in advertising (Rosen, 2012) and a better understanding of how it can be implemented will offer a key implication for digital marketing practice. This also provides implications for media creation and media buying- programmatic, using realtime bidding for inventory to place the customised adverts across mobile, display, video and social channels - even making its way into television (Vicioso, 2015).

With regards to the creative design of the advertisements, this chapter offers insight into persuasive elements in the development of positive attitudes in consumers (Shareef, Mukerji, Alryalat, Wright, \& Dwivedi, 2018), these creative elements have been decided through algorithms in anticipation that it will be emotionally appealing and can be shared on social media. (Alalwan, Rana, Dwivedi, \& Algharabat, 2017).

\section{$9 \quad$ Key Challenges}

Humans beings may be difficult to monitor and observed. Their browsing history may not be a true reflection of their personality and what appeals to their emotions. Since the process is based on this idea, there is a limitation in accurately capturing this information and presenting advertisements which reflects personal interest of the viewer.

This process may only work on the digital media as it may be too expensive and unpractical in other media. Digital media has the opportunity of reaching individuals on a personal level on social media, email marketing or on websites.

These personalised advertisements can be shared but it will be impractical to have a newspaper or billboard with personalised advertisements, however with the decline in readership of newspaper, that may not be an issue but with integration of beacons and camera on billboard, this can be possible as well for outdoor media.

Metrics on social media like the number of likes and retweets might not be a true reflection of the success and engagement rate of the advertisement. This is because the advertisements are personalised and it's not something seen by everyone and therefore 
there may not be a general consensus on its likes, however social media mention about how personal or unique it is can be monitored as an indication of its positive reception.

\section{Conclusion}

Acknowledging the role of personification in digital marketing and the role of digital service providers (Aswani, Kar, Ilavarasan, \& Dwivedi, 2018), this study offers a conceptual model that highlights the potential of incorporating artificial intelligence and machine learning into creative design of advertisements and digital marketing. It adds to existing knowledge on social media marketing and analysis (Kapoor, et al., 2018) and content design of advertisement for consumer exposure (Shareef, Dwivedi, Kumar, \& Kumar, 2017). It is acknowledged that this is an idea that has not being tested however this study is open for future research and development. The study extends knowledge on social media marketing (Alalwan, Rana, Dwivedi, \& Algharabat, 2017). Insight into the effectiveness of this strategy can also be explored which are however beyond the scope of this chapter. In addition, implications of this conceptual idea for mobile location-based advertising (Gutierrez, O'Leary, Rana, Dwivedi, \& Calle, 2018) can be explored further. Likewise, future research can explore the possibility of employing a personally administered structured questionnaire to gather information about participant's attitude towards emotionally appealing advertisements. In the post-development state, real data can be collected to understand how viewers are engaging with the advertisement. The new algorithm can be tested against the typical generic advertisements through an $\mathrm{A} / \mathrm{B}$ test. This $\mathrm{A} / \mathrm{B}$ test helps see if the consumers shown the personalised emotionally appealing advertisements engage better than the generic one. This can offer some justifications for this approach. Further implications for the advertiser, digital marketers and other professionals is presented as well.

\section{References}

\section{References}

Aaker, D. A., \& Stayman, D. M. (1992). Implementing the concept of transformational advertising. Psychology \& Marketing, 9(3), 237-253.

Aguirre, E., Mahr, D., Grewal, D., de Ruyter, K., \& Wetzels, M. (2015). Unraveling the personalization paradox: The effect of information collection and trustbuilding strategies on online advertisement effectiveness. Journal of Retailing, 91(1), 34-49.

Akbarpour, S. (2018). How Does GDPR Impact Advertising And E-Commerce? $\begin{array}{lllll}\text { Retrieved } & 8 & 8, & \text { from }\end{array}$ https://www.forbes.com/sites/forbesagencycouncil/2018/05/08/how-doesgdpr-impact-advertising-and-e-commerce/\#56ef557d3277 
Aksoy, Y., Oh, T., Paris, S., Pollefeys, M., \& Matusik, W. (2018). Yağız Aksoy, TaeHyun Oh, Sylvain Paris, 2018. Semantic Soft Segmentation. ACM Trans. Graph, 37(4), 1-13. doi:https://doi.org/10.1145/3197517.3201275

Alalwan, A. A., Rana, N. P., Dwivedi, Y. K., \& Algharabat, R. (2017). Social media in marketing: A review and analysis of the existing literature. Telematics and Informatics, 34(7), 1177-1190.

Antón, A. I., Earp, J. B., \& Young, J. D. (2010). How internet users' privacy concerns have evolved since 2002. IEEE Security \& Privacy, 8(1), 21-27.

Aswani, R., Kar, A. K., Ilavarasan, P. V., \& Dwivedi, Y. K. (2018). Search engine marketing is not all gold: insights from Twitter and SEOClerks. International Journal of Information Management, 38(1), 107-116.

Baek,, T. H., \& Morimoto, M. (2012). Stay away from me. Journal of Advertising, 41(1), 59-76.

Bidalgo. (2018). Home. Retrieved 2 2, 2018, from https://bidalgo.com/

Bleier, A., \& Eisenbeiss, M. (2015). The importance of trust for personalized online advertising. Journal of Retailing, 91(3), 390-409.

Boerman, S. C., Kruikemeier, S., \& Zuiderveen Borgesius, F. J. (2017). Online behavioral advertising: A literature review and research agenda. Journal of Advertising, 46(3), 363-376.

Brader, T. (2006). Campaigning for hearts and minds: How emotional appeals in political ads work. Chicago: University of Chicago Press.

Chandrashekar, A., Amat, F., Basilico, J., \& Jebara, T. (2017). Artwork Personalization at Netflix. Retrieved 2 2, 2918, from https://medium.com/netflixtechblog/artwork-personalization-c589f074ad76

Columbus, L. (2016). Ten Ways Big Data Is Revolutionizing Marketing And Sales. $\begin{array}{llll}\text { Retrieved } & 8 & 8, & 2018,\end{array}$ https://www.forbes.com/sites/louiscolumbus/2016/05/09/ten-ways-big-datais-revolutionizing-marketing-and-sales/\#1bfc272b21cf

Datameer. (2018). Unlocking the Customer's Mind With Retail Analytics. Retrieved 8 8, 2018, from https://www.datameer.com/blog/unlocking-customers-mindbig-data-retail-analytics/

Dawson, P., \& Lamb, M. (2016). Enhanced Success with Programmatic Social Advertising. In O. Busch (Ed.), Programmatic Advertising. Management for Professionals (pp. 103-110). Cham: Springer.

Decrop, A. (2007). The influence of message format on the effectiveness of print advertisements for tourism destinations. International Journal of Advertising, 26(4), 505-525.

Doland, A. (2016). CHECK OUT THE FIRST AD FROM MCCANN JAPAN'S 'AI CREATIVE DIRECTOR'. Retrieved 2 2, 2018, from http://adage.com/article/creativity/check-commercial-mccann-japan-aicreative-director/304320/

Dwivedi, Y. K., Kapoor, K. K., \& Chen, H. (2015). Social Media Marketing and Advertising. The Marketing Review, 15(3), 289-309.

Eyequant. (2018). Home. Retrieved 2 2, 2018, from http://www.eyequant.com/ 
Faggella, D. (2017). Artificial Intelligence and the Future of Programmatic Advertising. Retrieved 8 8, 2018, from https://www.techemergence.com/aifuture-programmatic-advertising/

Fontjoy. (2018). https://fontjoy.com/. Retrieved 2 2, 2018, from https://fontjoy.com/

Gökerik, M., Gürbüz, A., Erkan, I., Mogaji, E., \& Sap, S. (2018). Surprise me with your ads! The impacts of guerrilla marketing in social media on brand image. Asia Pacific Journal of Marketing and Logistics, 30(5), 1222-1238.

Greene, T. (2018). MIT made an image editing AI that can replace the background in any image. Retrieved 2 2, 2018, from https://thenextweb.com/artificialintelligence/2018/08/21/mit-made-an-image-editing-ai-that-can-replace-thebackground-in-any-image/

Gutierrez, A., O'Leary, S., Rana, N. P., Dwivedi, Y. K., \& Calle, T. (2018). 2018. Using privacy calculus theory to explore entrepreneurial directions in mobile location-based advertising: Identifying intrusiveness as the critical risk factor. Computers in Human Behavior. doi:https://doi.org/10.1016/j.chb.2018.09.015

Ha, L. (1996). Observations: advertising clutter in consumer magazines: dimensions and effects. Journal of Advertising Research, 36(3), 76-84.

Hitchcock, E. (2018). Five Big Data Use Cases for Retail. Retrieved 8 8, 2018, from https://www.datameer.com/blog/five-big-data-use-cases-retail/

Kalyanaraman, S., \& Sundar, S. S. (2006). The psychological appeal of personalized content in web portals: Does customization affect attitudes and behavior? Journal of Communication, 56(1), 110-132.

Kapoor, K. K., Tamilmani, K., Rana, N. P., Patil, P., Dwivedi, Y. K., \& Nerur, S. (2018). Advances in Social Media Research: Past, Present and Future. Information Systems Frontiers, 20(3), 531-558.

Kihn, M. (2016). Customer Journey Analytics: A Manifesto. Retrieved 8 8, 2018, from https://blogs.gartner.com/martin-kihn/customer-journey-analytics-amanifesto/

Kulbok, K. (2017). What is programmatic advertising? A beginner's guide. Retrieved 8 8, 2018, from https://www.marketingweek.com/2017/03/27/programmaticadvertising/

Kumar, V., \& Gupta, S. (2016). Conceptualizing the Evolution and Future of Advertising. Journal of Advertising, 45(3), 302-317.

Li, C., \& Liu, J. (2017). A name alone is not enough: A reexamination of web-based personalization effect. Computers in Human Behavior, 72, 132-139.

Li, Z. (2017). The "Celeb" Series: A Close Analysis of Audio-Visual Elements in 2008 US Presidential Campaign Ads. Undergraduate Journal of Humanistic Studies, 4(1), 1 - 16.

Mezo, R. E. (1997). An adaptation of aristotle: A note on the types of oratory. Rhetoric Review, 16(1), 164-165.

Mogaji, E. (2016). Emotional Appeals in UK Banks' Print Advertisement. Luton, Bedfordshire: University of Bedfordshire, Unpublished $\mathrm{PhD}$ Thesis.

Mogaji, E. (2018). Emotional Appeals in Advertising Banking Services. London: Emerald. 
Mogaji, E., \& Danbury, A. (2017). Making the brand appealing: advertising strategies and consumers' attitude towards UK retail bank brands. Journal of Product \& Brand Management, 26(6), 531-544.

Mogaji, E., \& Erkan, I. (2019). Insight into consumer experience on UK train transportation services. Travel Behaviour and Society, 14, 21-33.

Mogaji, E., \& Farinloye, T. (2017). Attitudes towards brands and advertisements: qualitative and thematic analysis of social media data. In B. Rishi, \& S. Bandyopadhyay (Eds.), Contemporary Issues in Social Media Marketing (pp. 206-216). London: Routledge.

Mogaji, E., Czarnecka, B., \& Danbury, A. (2018). Emotional appeals in UK businessto-business financial services advertisements. International Journal of Bank Marketing, 36(1), 208-227.

Mogaji, E., Farinloye, T., \& Aririguzoh, S. (2016). Factors shaping attitudes towards UK bank brands: An exploratory analysis of social media data. Cogent Business \& Management, 3(1), 1223389.

O’Guinn, T., Allen, C., \& Semenik, R. (2006). Advertising and Integrated Brand Promotion (4th ed.). Mason, OH: Thomson South-Western.

Panda, T. K., Panda, T. K., \& Mishra, K. (2013). Does emotional appeal work in advertising? The rationality behind using emotional appeal to create favorable brand attitude. IUP Journal of Brand Management, 10(2), 7-23.

Persado. (2018). Home. Retrieved 8 8, 2018, from https://www.persado.com/

Phrasee. (2018). Home. Retrieved 8 8, 2018, from https://phrasee.co/

Plummer, L. (2017). Fontjoy website uses machine learning to perfectly pair fonts. Retrieved 2 2, 2018, from https://www.fastcompany.com/90129005/can-amachine-choose-fonts-and-colors-better-than-you-try-it

Rosen, J. (2012). Who Do Online Advertisers Think You Are? Retrieved 2 2, 2018, from https://www.nytimes.com/2012/12/02/magazine/who-do-online-advertisersthink-you-are.html?pagewanted=all\&_r=0

Rust, R. T. (2016). Comment: Is Advertising a Zombie? Journal of Advertising, 45(3), 346-347.

Salander, B. (2010). Emotionality in Business-to-business Marketing communications. Newcastle: University of Northumbria at Newcastle, Unpublished PhD Thesis.

Schiffer, J. (2015, 7 7). I SECOND THAT EMOTION: THE EMOTIVE POWER OF MUSIC IN ADVERTISING MEDIA. Retrieved 12 15, 2016, from Nielsen.com: http://www.nielsen.com/us/en/insights/news/2015/i-secondthat-emotion-the-emotive-power-of-music-in-advertising.html

Shareef, M. A., Dwivedi, Y. K., Kumar, V., \& Kumar, U. (2017). Content design of advertisement for consumer exposure: Mobile marketing through short messaging service. International Journal of Information Management, 37(4), 257-268.

Shareef, M. A., Mukerji, B., Alryalat, M. A., Wright, A., \& Dwivedi, Y. K. (2018). Advertisements on Facebook: Identifying the persuasive elements in the development of positive attitudes in consumers. Journal of Retailing and Consumer Services, 43, 258-268. 
Stanton, J. V., \& Guion, D. T. (2013). Taking Advantage of a Vulnerable Group? Emotional Cues in Ads Targeting Parents. Journal of Consumer Affairs, 47(3), 485-517.

Takahashi, D. (2018). Bidalgo uses AI to make mobile advertising more creative. Retrieved 8 8, 2018, from https://venturebeat.com/2018/07/26/bidalgo-usesai-to-make-mobile-advertising-more-creative/

Tran, T. P. (2017). Personalized ads on Facebook: An effective marketing tool for online marketers. Journal of Retailing and Consumer Services, 39, 230-242.

Tucker, C. E. (2014). Social networks, personalized advertising, and privacy controls. Journal of Marketing Research, 51(5), 546-562.

Ukpabi, D., Karjaluoto, H., Olaleye, S., \& Mogaji, E. (2018). Dual perspectives on the role of artificially intelligent robotic virtual agents in the tourism, travel and hospitality industries. 11th Annual Conference of the EuroMed Academy of Business. Research Advancements in National and Global Business Theory and Practice (pp. 1355-1367). Valletta, Malta: EuroMed Academy of Business.

Ukpabi, D., Karjaluoto, H., Olaleye, S., \& Mogaji, E. (2019). Influence of Offline Activities and Customer Value Creation on Online Travel Community Continuance Usage Intention. In Information and Communication Technologies in Tourism (pp. 450-460). Cham: Springer.

Vicioso, S. (2015). PROGRAMMATIC ADVERTISING 101: HOW IT WORKS. Retrieved 2 2, 2018, from http://www.seerinteractive.com/blog/programmatic-advertising-101-works/

Williams, E. (2018). The Role of AI in Redefining the Programmatic Advertising Experience. $\quad$ Retrieved 8 8, 2018, from https://www.martechadvisor.com/articles/ads/the-role-of-ai-in-redefiningthe-programmatic-advertising-experience/

Wilson, M. (2017). Can A Machine Choose Fonts And Colors Better Than You? Try It. Retrieved 2 2, 2018, from https://www.fastcompany.com/90129005/can-amachine-choose-fonts-and-colors-better-than-you-try-it 